\title{
The PREVASC study: the clinical effect of a multifaceted educational intervention to
} prevent childhood asthma

\author{
H.J.A.M. Schönberger*, E. Dompeling\#, J.A. Knottnerus*, T. Maas*, \\ J.W.M. Muris*, C. van Weel ${ }^{\star}$ and C.P. van Schayck*
}

ABSTRACT: As asthma is the most common chronic disease in childhood, much attention is directed towards primary prevention. Here, the clinical effectiveness of a multifaceted educational prevention was studied.

A total of 476 high-risk children were recruited during the prenatal period by general practitioners and randomised to either: 1) a control group, receiving usual care; or 2) an intervention group in which families received instruction from nurses on how to reduce exposure of newborns to mite, pet and food allergens, and passive smoking.

A total of 443 infants were followed-up for 2 yrs. At 2 yrs of age, the intervention group $(n=222)$ had less asthma-like symptoms, including wheezing, shortness of breath and night-time cough, than the control group $(n=221)$. No significant differences in total and specific immunoglobulin $E$ were found between the groups. During the first 2 yrs of life, the incidence of asthma-like symptoms was similar in both groups; however, subanalysis revealed a significant reduction in the female, but not in the male, intervention group.

In conclusion, the intervention used in this study was not effective in reducing asthma-like symptoms in high-risk children during the first 2 yrs of life, although it was modestly effective at 2 yrs. Follow-up is necessary to confirm whether the intervention can actually prevent the development of asthma.

KEYWORDS: Childhood asthma, house dust mites, passive smoking, pets, prevention, primary care

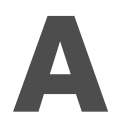
sthma is the most common chronic disease in childhood and it is responsible for a large burden of disease, with huge socio-economic consequences [1-3]. As the prevalence of asthma is still increasing [4-8], much attention is being directed towards the possibilities for primary prevention. It is generally agreed that asthma is a multifactorial disease, which develops in very early life or even in the uterus [9-12].

Environmental exposure to allergens and tobacco smoke during pregnancy or in very early life may enhance sensitisation and allergic morbidity, especially in children with a genetic predisposition $[13,14]$. Several primary prevention trials are currently in progress or will be finished soon, and have recently been reviewed [15]. Some trials study the preventive effect of a reduction in a single exposure, such as food allergens [16], or mite and pet allergens $[17,18]$, or a dual approach of avoidance of food and mite allergens
[19], combined with a reduction in passive smoking [20]. The study reported here, the Prevention of Asthma in Children (PREVASC) study, differs from the previously cited trials, as eligible cases were recruited from a primary care population in a routine primary care setting. The study uses a multifaceted approach, by investigating the effect of a reduction in both prenatal and postnatal exposure to mite, pet and food allergens, and passive tobacco smoke on the development of asthma in children at high risk, those with at least one first-degree relative with asthma. Through this approach the PREVASC study acknowledges the multifactorial nature of asthma. It brings together the factors that can be addressed in daily primary care. In addition, a comprehensive preventive effect, rather than the effect of a reduction of a single exposure, is assessed. Since airway morbidity is influenced by sex [21], and sex-specific effects of environmental exposure on asthma have been reported recently [22], the clinical effectiveness of the

\section{AFFILIATIONS}

Depts of ${ }^{*}$ General Practice, and \#Paediatric Pulmonology, Research Institute CAPHRI, University Hospital Maastricht, Maastricht, and

"Dept of General Practice, University Medical Centre, Radboud University Nijmegen, Nijmegen, The Netherlands.

CORRESPONDENCE

H.J.A.M. Schönberger

Dept of General Practice

Research Institute CAPHRI

University Maastricht

Cannerweg 289

6213 BE Maastricht

The Netherlands

Fax: 31433100663

E-mail: Huub.Schonberger@

hag.unimaas.nl

Received:

June 082004

Accepted after revision:

December 072004

SUPPORT STATEMENT

The study was funded by The Dutch Asthma Foundation, Prevention Fund and Royal Academy of Science (KNAW). No competing interests were declared.

European Respiratory Journal Print ISSN 0903-1936 Online ISSN 1399-3003 
intervention programme was evaluated separately in males and females.

\section{METHODS}

The Ethical Committee of the University Maastricht (Maastricht, The Netherlands) approved the study.

\section{Study population}

The PREVASC study is a randomised intervention study carried out in the Dutch primary care setting, investigating the effectiveness of a primary prevention programme of asthma directed towards high-risk families expecting a child. The rationale and design of the PREVASC study have been described previously [14, 23].

In summary, pregnant mothers were recruited by general practitioners (GPs) and midwives during the first two trimesters of their pregnancy when they visited their GP or midwife. In the Dutch healthcare system, all patients are registered with a GP over a long period of time and consult their GP for all their healthcare needs, including pregnancy [24]. Mothers were asked for written informed consent when the GP had established that their unborn babies were at high risk from familial occurrence of asthma (asthma in at least the mother, father or sibling(s)). This allowed antenatal identification of those who would subsequently be at increased risk of developing asthma.

\section{Intervention}

The intervention group received standardised instruction from (specially trained) nurses in three home visits: at the start at 46 months of pregnancy, at 8 months of pregnancy, and 1-3 weeks after birth. The instruction consisted of recommendations to reduce four main environmental exposures, as follows. 1) Mite allergens by sanitation measures, including daily cleaning of floors in the house, washing bed clothes on a hot cycle $\left(\geqslant 60^{\circ} \mathrm{C}\right)$, removing textile floor coverings, reducing air humidity by ventilating/airing and heating, using miteimpermeable bedding (mattress, quilt and pillow, and/or sleeping bag) for both parents and infant (Mitecare ${ }^{\circledR}$; Sanalife BV, Lelystad, The Netherlands). These measures have been shown to be effective in reducing mite allergen levels [14]. Parents were informed of these anti-mite measures during the second visit and they were encouraged to apply them before the infant was born and during the first 2 yrs of life. Anti-mite encasings were provided 1 month before birth. 2) Pet allergens by disposing of pets or keeping them outside the house and washing them at least once a month. Instruction on these measures was given during the first visit and repeated in the second and third visits. Parents were asked to start by applying the measure at least 3 months before birth and to continue this during the first 2 yrs of life. The timing of the instruction to apply these two measures was chosen so that a low level of these allergens could be achieved by the time the child was born. 3) Food allergens by breastfeeding the infant during at least the first 6 months of life. If breastfeeding was stopped before a child was 6 months old or if supplementation was necessary, an extensive hydrolysed formula milk (Nutrilon Pepti®; Numico, Zoetermeer, The Netherlands) was prescribed. In addition, it was recommended that the introduction of the first solid food intake was postponed until after 6 months of age. Instruction on these measures was given during the second visit and repeated during the third visit. 4) Passive smoking during pregnancy by maternal abstention from smoking and postnatally by parental abstention from smoking in the first 2 yrs of life. Instruction on these measures was given during the first visit and repeated during the second and third visits.

The control group received usual care provided by the GP. In the guidelines of the Dutch College of General Practitioners on asthma in children [25], preventive measures are recommended only when children are already asthmatic (secondary prevention). Measures to prevent asthma in high-risk infants are currently not part of the guidelines.

\section{Outcome variables}

The primary clinical outcome variables were symptoms that might point at a possible development of asthma (referred to as asthma-like symptoms) at any time in the first 2 yrs of life and during the last month of the 2nd year of life (referred to as current symptoms). Symptoms were derived from parental and GP reports.

For measuring the occurrence of asthma-like symptoms in the first 2 yrs of life, questionnaires from the International Study of Asthma and Allergies in Childhood (ISAAC) were used [26], administered at the following ages: 6 months, 1 and 2 yrs. In order to enable comparisons of the results, ISAAC outcomes were brought into line with those used in other primary prevention studies [18]. The items studied included: "nighttime cough without cold", "wheezing at least once", "wheezing with awakening" and "recurrent wheezing" (more than 4 times) at any time in the first 2 yrs of life.

Current asthma-like symptoms included "wheeze", "shortness of breath" and "night-time coughing", and were derived from parental reports on these symptoms in the 4 weeks prior to the child's 2nd birthday.

GP reports consisted of prospectively recorded asthma-like symptoms ("wheezing without fever", "shortness of breath" and "coughing") observed when the parents consulted the GP when their child was ill during the first 2 yrs of life. In addition, standardised diagnoses (atopic dermatitis, bronchi(oli)tis and pneumonia) were recorded, based on definitions of the International Classification of Health Problems in Primary Care (ICHPPC) [27]. As a gold standard for asthma at 0-4 yrs is lacking, asthma diagnosis was based on the Dutch Guideline "Asthma in Children" (further referred to as GP-based diagnosis asthma) [25].

\section{Measurement of IgE}

Atopic status was determined at 2 yrs of age by the measurement of total and specific immunoglobulin $(\mathrm{Ig}) \mathrm{E}$ against mite (Der p1), cat (Fel d1) and dog (Can f1) allergens. Total and specific IgE were determined in heel-prick blood, sampled on filter paper at 2 yrs. Absorbed material was eluted by incubation with phosphate buffered saline (PBS)-T (PBS/Tween-20 $(0.1 \% \mathrm{v} / \mathrm{v}))$ for $16 \mathrm{~h}$ under constant rotation. Elutants were separated from filter paper by centrifugation. Determination of total $\mathrm{IgE}$ in eluted blood spots was performed as previously described [28] using sepharoseimmobilised reagents and ${ }^{125} \mathrm{I}$-labelled anti-IgE raised in sheep. 
Test results were expressed in IU per mL (1 IU representing $\sim 2.4 \mathrm{ng}$ of $\mathrm{IgE})$.

Specific IgE against mite, cat and dog were assessed with a radio-allergosorbent fluorescent immunoassay (RAST).

\section{Measurement of environmental exposures to mite, pet and food allergens, and passive smoking}

The effect of the intervention, with respect to mite and pet allergens, was measured by comparing mite, cat and dog allergen levels in three settled dust reservoirs (the living room floor, parental and infant mattresses) at baseline, directly after enrolment (3-5 months before birth) and exactly 1 yr later (7-9 months after birth), in order to avoid seasonal influences in allergen levels [29]. At the same time, dust samples were taken in the control group. Dust collecting was performed by research assistants in a standardised manner, by vacuuming (1300-W-vacuum ${ }^{\circledR}$; Bosch, Rotterdam, The Netherlands) the living room floor (two areas of $1 \mathrm{~m}^{2}$, for $2 \mathrm{~min}$ ) and the parental and crib mattresses $\left(1 \mathrm{~m}^{2}\right.$, for $\left.2 \mathrm{~min}\right)$ with covers but without sheets. The preparation of dust samples for measurement, and the measurement of Der p1, Fel d1 and Can f1 have been described previously [30]. One IU Can $\mathrm{f} 1$ corresponds to 1 ng Can f1, whereas $1 \mathrm{mU}$ Fel d1 corresponds to $4 \mathrm{ng}$ Fel d1. The detection limit was $2 \mathrm{ng} \cdot \mathrm{g}^{-1}$ of dust for Der $\mathrm{p} 1$, and $1 \mathrm{ng} \cdot \mathrm{g}^{-1}$ of dust for Fel $\mathrm{d} 1$ and Can $\mathrm{f} 1$. Allergen concentrations were calculated as ng per metre squared vacuumed surface [31].

Data on exposure to food allergens (breastfeeding and/or type of formula feeding) were derived from weekly diary recording and, in the case of the introduction of solid foods, a questionnaire when the child was 6 months old.

Prenatal and postnatal passive smoking were assessed on the basis of a parentally recorded questionnaire when the child was 1 yr old.

\section{Randomisation}

As blinding for the intervention measures was not possible, families were allocated to the intervention and control groups by pre-randomisation (randomised consent design, in which both groups were informed about their own trial arm but not about the other [32]). To prevent contamination between the intervention group and the control group, the prerandomisation was performed in clusters, taking into account the post (zip) code of the domicile of the recruited family in combination with the location of the general practice the family attended. Once a general practice was allocated, every family subsequently recruited in that practice was allocated automatically to the same group. In this way, 242 families, recruited in 106 general practices with $\sim 2.4 \pm 3.4$ (SD) patients per practice, were allocated to the intervention group; and 234 families, recruited by 146 general practices with $\sim 1.6 \pm 1.8$ (SD) patients per practice, were allocated to the control group.

\section{Analysis}

Differences in baseline characteristics and exposures between the intervention and control groups were tested using the Chi-squared test for proportions and the unpaired t-test for normally distributed continuous variables. The dependent variables reported and observed at age 2 yrs included asthma-like morbidity, atopic dermatitis, and total and specific IgE. Some data on the frequency of smoking $(23(10 \%)$ and 17 $(8 \%)$, in the intervention and control groups, respectively) and of breastfeeding (14 (6.3\%) and $2(1 \%)$, in the intervention and control groups, respectively) were missing. Therefore, analyses were performed: 1 ) considering missing data as such (adherersonly analysis); and 2) considering cases with incomplete smoking data as passive smokers and those without breastfeeding data as not being breastfed. Differences in morbidity outcome between the groups were expressed as odds ratios (OR) with 95\% confidence intervals (95\% CI).

Total IgE data were normally distributed after logarithmic transformation.

In a post hoc analysis, the comparisons between the intervention and control groups were repeated separately for males and females.

As bed-sharing of infants and parents is very common [33], and as children are also exposed to allergens in the living room, the mean of the specific allergen concentrations measured in the parental and crib mattress dust and in the living room dust was calculated for each case, to obtain an overall measure of infant allergen exposure.

As the concentrations of mite, cat and dog allergens in samples of house dust and mattresses were not normally distributed even after logarithmic transformation, their median levels were used for the estimation of the effect of allergen-reducing measures. In addition, to assess the independent effects of the exposure to mite, pets and food allergens, and of passive smoking on the outcome measures, multiple logistic regression analysis was performed. Differences between the groups were tested using the Mann-Whitney U-test and within the groups using the Wilcoxon signed-rank test. A two-sided p-value $<0.05$ was considered to be significant.

\section{RESULTS}

\section{Study population}

From 1997-2000, 476 families were recruited, of whom 93\% $(n=443)$ completed the 2 -yr study period. Figure 1 shows the trial profile. After 2-yrs' follow-up, $9 \%(n=20)$ in the intervention group and $6 \%(n=13)$ in the control group dropped out, resulting in the participation of 222 families in the intervention group and 221 in the control group. No differences in baseline socio-demographic characteristics were found between the intervention and control groups, either as a whole or within the subgroups of males and females, with the exception of lower mite allergen levels in the control group (table 1). Significantly more intervention families than control families enrolled in the autumn/winter: 182 (82\%) versus 152 (69\%), $p=0.001$. Baseline mite allergen levels were found to be lower in the control group than in the intervention group, and this was also the case when analysed within the male and female groups (table 1).

After 2-yrs' follow-up, some data on applied intervention measures were missing. However, they were equally divided between the intervention and control groups. There were no indications for a selective item nonresponse (data not shown). 


\section{Pregnant females who met inclusion criteria and gave informed content} $n=476$

\section{Cluster randomisation on postcode and general practice}

Allocated to the intervention group $\mathrm{n}=242$ patients recruited in 106 general practices

\section{Families dropped out $n=20$}

(abortion $n=11$; still birth $n=2$; moved $n=4$; withdrawal $n=3$ )

Children completed the study $n=222$
Allocated to the control group $\mathrm{n}=234$ patients recruited in 140 general practices

Families dropped out $n=13$

(abortion $\mathrm{n}=6$; long-lasting hospitalisation $\mathrm{n}=2$; still birth $\mathrm{n}=1$; moved $n=3$; withdrawal $n=1$ )

FIGURE 1. Trial profile of the Prevention of Asthma in Children (PREVASC) study after recruitment.

\section{The effect of the intervention programme on exposure}

The effect of the intervention programme on exposure to food allergens and passive smoking is shown in figure 2, and to mite and pet allergens in figure 3 .

Infants in the intervention group, when compared to the control group, were considerably more exclusively breastfed and/or received more hypoallergenic bottle feeds. The intervention group received their first solid food less frequently before they were 6 months old when compared with the control group. Prenatal and postnatal exposure to smoking were equal for the intervention and the control groups.

One year after baseline measurements, mite, cat and dog allergen concentrations were significantly lower in the

TABLE 1 Demographic and other baseline characteristics of the control and intervention groups stratified for sex

\begin{tabular}{|c|c|c|c|c|c|c|}
\hline & \multicolumn{2}{|c|}{ Total } & \multicolumn{2}{|c|}{ Males } & \multicolumn{2}{|c|}{ Females } \\
\hline & Intervention & Control & Intervention & Control & Intervention & Control \\
\hline Subjects n & 222 & 221 & 118 & 111 & 104 & 110 \\
\hline Age yrs mother & $30.9 \pm 3.8$ & $31.0 \pm 3.6$ & $31.1 \pm 4.1$ & $30.7 \pm 3.7$ & $30.7 \pm 3.5$ & $31.3 \pm 3.4$ \\
\hline Low education" mother & $2(14.5)$ & $20(9.0)$ & $17(14.4)$ & $12(10.8)$ & $15(14.6)$ & $8(7.3)$ \\
\hline Mother & $118(53.4)$ & $111(50.7)$ & $60(51.3)$ & $59(53.6)$ & $58(55.8)$ & $52(47.7)$ \\
\hline Siblings & $83(60.1)$ & $95(68.3)$ & $43(59.7)$ & $46(65.7)$ & $40(60.6)$ & $49(71.0)$ \\
\hline Birth weight & 3387 (528) & $3475(583)$ & $3438(569)$ & $3492(624)$ & $3329(474)$ & 3465 (538) \\
\hline Pregnancy duration weeks & $39.7(1.7)$ & $39.7(1.6)$ & $39.6(1.8)$ & $39.7(1.8)$ & $39.7(1.4)$ & $39.7(1.6)$ \\
\hline Delivery at home & $71(32.0)$ & $81(36.7)$ & $34(28.8)$ & $46(41.8)$ & $37(35.6)$ & $35(31.8)$ \\
\hline Uncomplicated delivery & $172(77.8)$ & $168(76.0)$ & $85(72.6)$ & $81(73.6)$ & $87(83.7)$ & $86(78.2)$ \\
\hline \multicolumn{7}{|l|}{ Exposure at baseline } \\
\hline Der p1 $\mathrm{ng} \cdot \mathrm{m}^{-2}(\mathrm{IQR})^{\bullet}$ & $148(1421)^{+}$ & $79(474)^{\star \star \star}$ & $136(1670)^{+}$ & $88(484)^{\star \star}$ & $193(1617)^{+}$ & $65(380)^{\star *}$ \\
\hline Fel d1 $\mathrm{ng} \cdot \mathrm{m}^{-2}(\mathrm{IQR})^{\circ}$ & $94(244)$ & $73(288)$ & $96(285)$ & $83(362)$ & $96(288)$ & $69(278)$ \\
\hline Can f1 $n g \cdot m^{-2}(I Q R)^{\bullet}$ & $34(274)$ & $39(258)$ & $26(356)$ & $40(533)$ & $42(255)$ & $42(184)$ \\
\hline Smoking mother & $28(14.1)$ & $32(15.7)$ & $16(15.1)$ & $22(22.0)$ & $12(12.9)$ & $10(9.6)$ \\
\hline Smoking father & $46(24.1)$ & $46(23.5)$ & $24(24.0)$ & 28 (29.2) & $22(24.2)$ & $18(18.0)$ \\
\hline Presence of cat or dog & $62(31.5)$ & $71(34.9)$ & $35(32.7)$ & $39(39)$ & 27 (29.3) & $32(31.7)$ \\
\hline
\end{tabular}

Data are presented as $n(\%)$ or mean \pm SD, unless otherwise stated. \#: only primary school; ${ }^{\circ}$ : calculated as the mean level of the median amount of the specific allergen levels in dust from parental and infant mattresses and living room floor. ${ }^{* *}: p<0.01 ;{ }^{* *}: p<0.001 ;{ }^{+}$: statistically significant, intervention versus control group. 

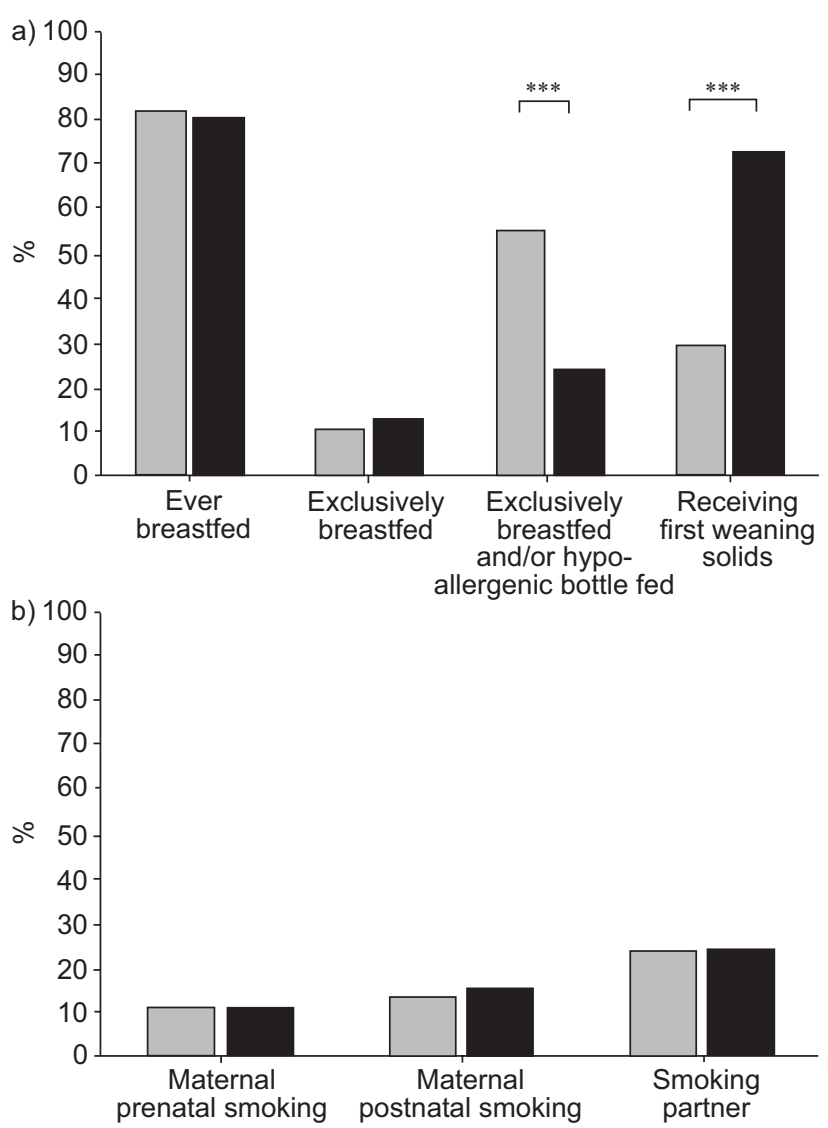

FIGURE 2. Effectiveness of the Prevention of Asthma in Children (PREVASC) intervention programme on a) feeding practice in the first 6 months of life and b)

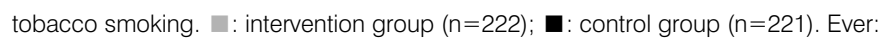
at least 1 week. ***: $p<0.001$, using Pearson's Chi-squared test.

intervention group than in the control group (fig. 3). The same results were found within the male and female groups (data not shown).

\section{Clinical effectiveness}

Parentally reported and GP-based symptoms and diagnoses Table 2 shows the frequencies of the asthma-like symptoms in the intervention and control groups, and their risk estimates with $95 \%$ CI. No differences were found between the groups for parentally reported and GP-observed asthma-like symptoms during the first 2 yrs. The same held for the GP-based diagnosis of asthma. Parentally reported current asthma-like symptoms occurred significantly less in the intervention group compared with the control group (table 2).

When analysed for females and males separately, both asthmalike symptoms in the first $2 \mathrm{yrs}$ of life, as well as current symptoms, occurred significantly less among females in the intervention group than in the female control group, whereas there was no difference amongst males. This was the case for parentally reported symptoms during the first 2 yrs of life or current symptoms (fig. 4), as well as for GP-observed symptoms (fig. 5). In the female intervention group, GP diagnosis of asthma tended to be less frequently present $(p=0.08)$ compared with the female control group, whereas among males this was not the case.

\section{Serum IgE levels}

The mean serum concentration of total IgE was similar for the intervention and control groups (table 3). In addition, mite-, cat- and dog-specific IgE were similar in both groups. Separate subanalysis of the outcomes for males and females revealed that females in the intervention group tended to be less sensitised against mites, whereas the opposite was observed in the male group, although the differences did not reach statistical significance $(p=0.09$; table 3$)$.

When the analyses on the association between asthma-like and atopic morbidity were repeated, assuming that the children with missing data on smoking and breastfeeding behaviour were exposed to passive smoke and were not breastfed, respectively, the results did not change essentially (data not shown).
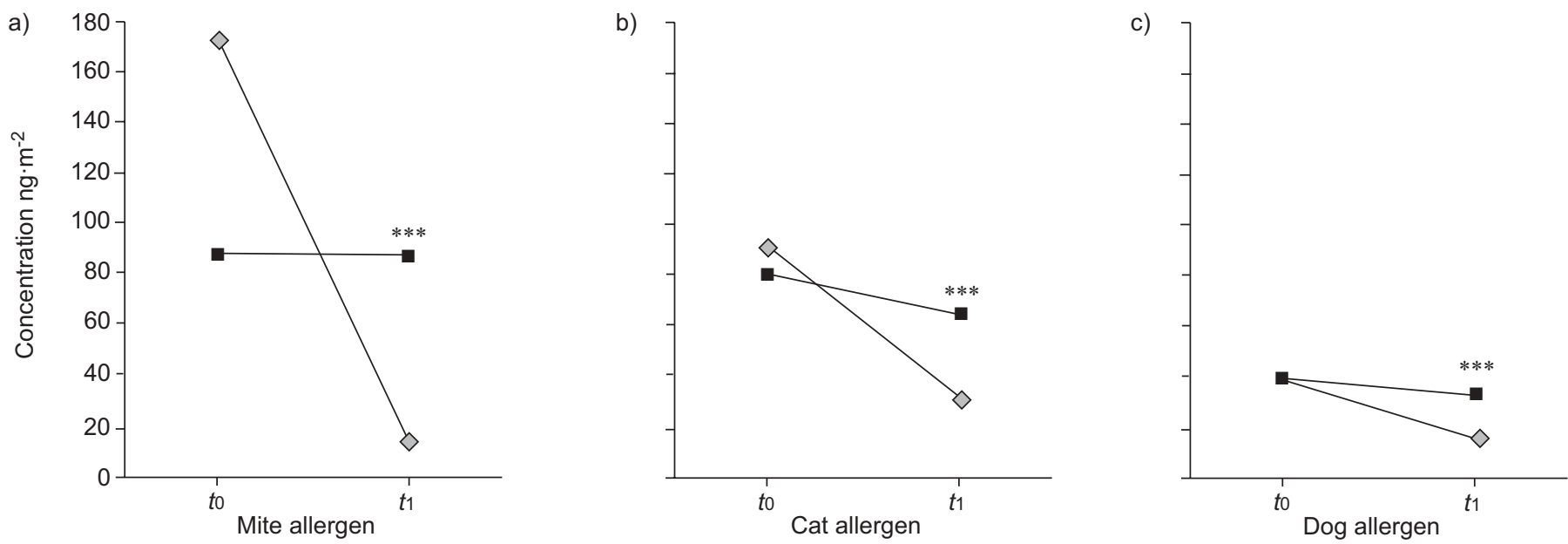

FIGURE 3. Effectiveness of the Prevention of Asthma in Children (PREVASC) programme on exposure to mite and pet allergens. Median overall concentrations of a) mite, b) cat and c) dog allergens in dust samples of living room, parental and infant mattresses at baseline (to) and 1 yr later (t1) for the intervention group ( $\square$ ) and the control group ( $\mathbf{\square})$. ${ }^{* \star}: \mathrm{p}=0.001$, intervention versus control group after the intervention (t1), using Mann-Whitney U-test. 
TABLE 2 Occurrence of asthma-like symptoms and allergic morbidity at 0-2 yrs and at $2 \mathrm{yrs}$ in the intervention and control groups

\begin{tabular}{|c|c|c|c|}
\hline \multicolumn{4}{|l|}{ Parentally reported symptoms at $0-2$ yrs } \\
\hline Wheezing with awakening at least once & $14(26 / 188)$ & $17(30 / 182)$ & $0.88(0.45-1.7)$ \\
\hline Recurrent wheezing $\geqslant 4$ times & $26(49 / 189)$ & $26(47 / 184)$ & $1.1(0.61-2.0)$ \\
\hline Night-time cough without a cold at least once & $48(95 / 197)$ & $53(101 / 190)$ & $0.78(0.46-1.3)$ \\
\hline Shortness of breath & $16(30 / 187)$ & $25(43 / 171)$ & $0.76(0.61-0.96)^{\bullet}$ \\
\hline Night-time cough & $44(57 / 184)$ & $56(72 / 168)$ & $0.72(0.55-0.95)^{\bullet}$ \\
\hline \multicolumn{4}{|l|}{ GP-recorded morbidity at $0-2$ yrs } \\
\hline Wheezing without fever at least once & $34(72 / 212)$ & $40(80 / 200)$ & $0.87(0.72-1.1)$ \\
\hline Shortness of breath at least once & $27(57 / 212)$ & $31(62 / 200)$ & $0.90(0.73-1.1)$ \\
\hline
\end{tabular}

Data are presented as \% $(\mathrm{n} / \mathrm{N})$, unless otherwise stated. GP: general practitioner; OR: odds ratio; Cl: confidence interval. \#: at least one diary-reported episode in the last 4 weeks before the 2 nd birthday; ${ }^{\prime}$ : significant effects.

\section{Relationship between exposure and asthma-like morbidity}

Table 4 shows the ORs for asthma-like symptoms for the group as a whole (the intervention and control group together) in relation to exposure to mite, cat, dog and food allergens, and passive smoking, adjusted for each other in a multiple logistic regression analysis. Being breastfed ( $\geqslant 1$ week) from birth decreased the risk of current asthma-like symptoms at 2 yrs. Abstinence from maternal smoking reduced the risk of recurrent wheeze and of current wheeze at 2 yrs. Low mite levels significantly decreased the risk of current wheezing and shortness of breath.

\section{DISCUSSION}

The PREVASC study is the first study in a primary care environment to investigate the clinical effectiveness of a multifaceted approach aimed to prevent the development of asthma in high-risk children.

The results of this study indicate that the intervention was able to reduce exposure to mite, pet and food allergens, but not to passive smoking. Despite this reduction, there was no effect on either parentally reported or GP-observed symptoms during first 2 yrs of life, nor on total and specific $\operatorname{IgE}$ at 2 yrs. However, asthma-like symptoms at the end of the 2nd yr were less frequently reported in the intervention group. Moreover, the decrease appeared to be more pronounced in and mainly confined to the females in the intervention group.

The intervention might have caused the differences in symptoms at the end of the 2nd yr, but other explanations
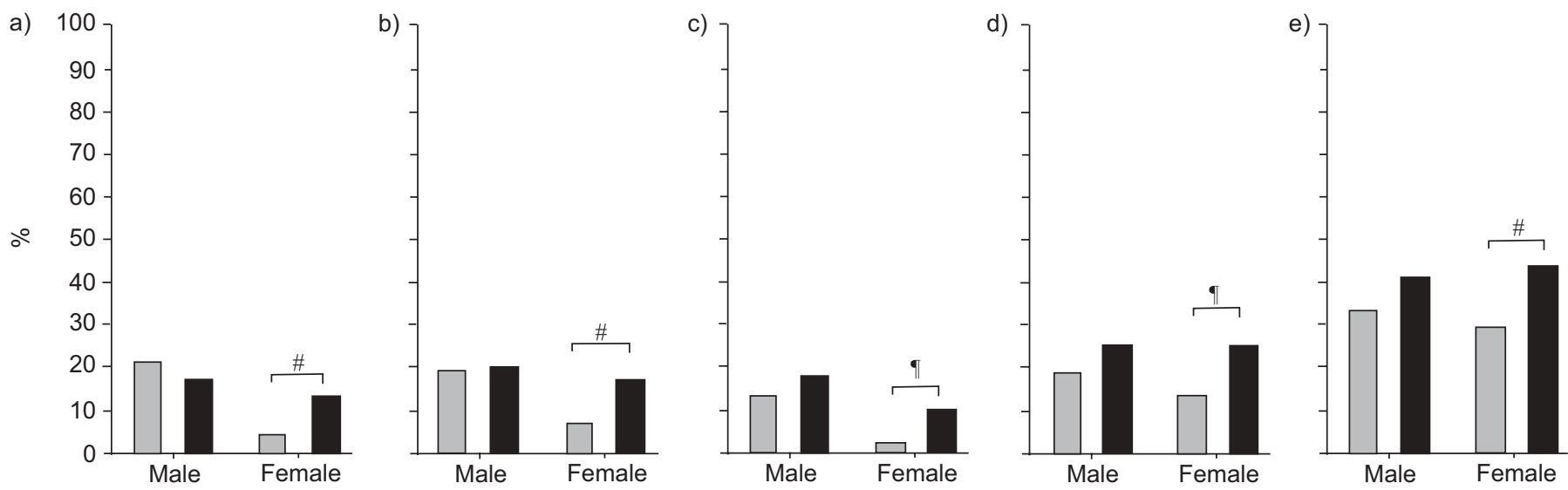

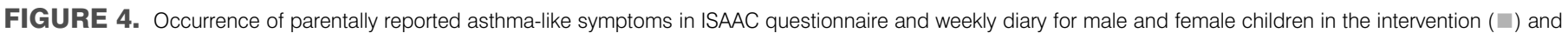

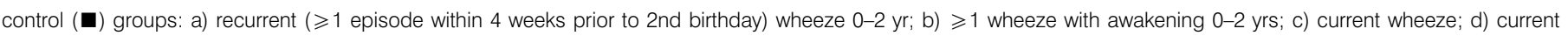
shortness of breath; and e) current nightly coughing. ${ }^{*}: p=0.04 ;{ }^{\bullet}: p=0.03$. 

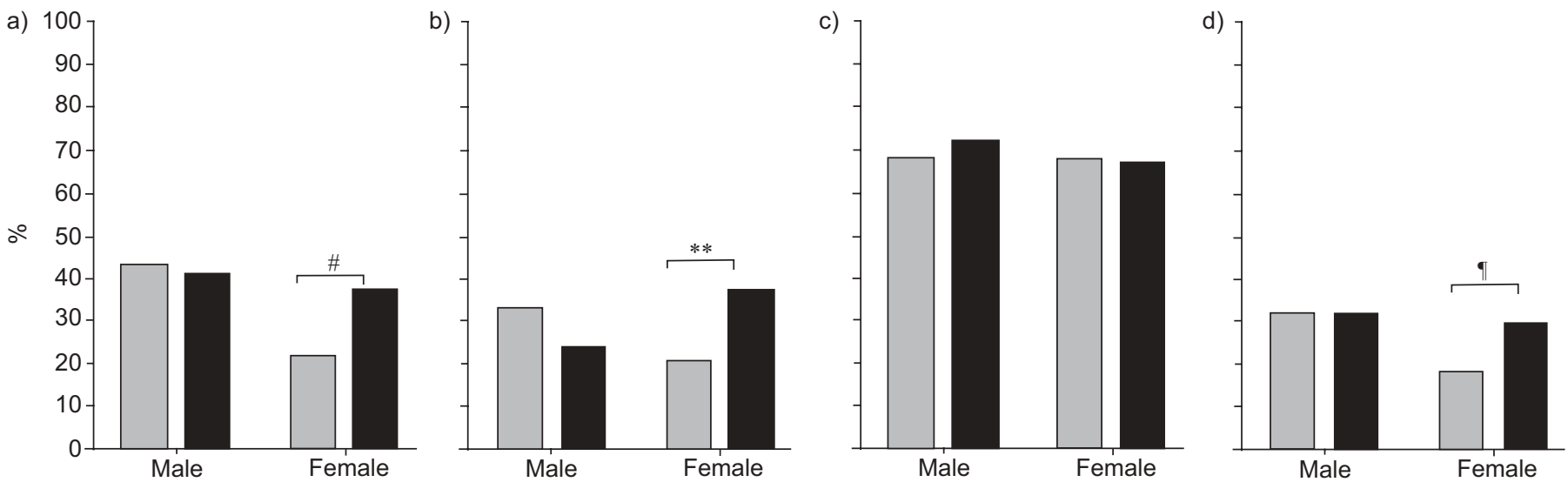

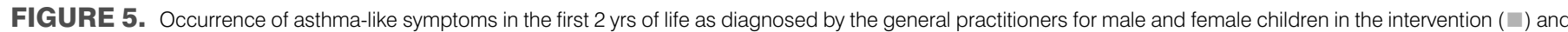
control ( $\mathbf{\square}$ ) groups: a) wheezing without fever; b) shortness of breath; c) coughing; and d) diagnosis of asthma. **: $p=0.01 ;{ }^{*}: p=0.02 ;{ }^{\bullet}: p=0.08$.

for the reported decrease in current asthmatic symptoms also have to be considered. A major limitation is the fact that most of the environmental exposure-reducing measures, including breastfeeding, weaning practices, procuring pets and smoking, cannot be blindly executed. All birth cohort intervention studies experience this problem $[17,20]$. Therefore, reporting bias cannot be excluded as an explanation for the decrease in asthma-like symptoms in the intervention group at age 2 yrs. Parents in the intervention group are aware of the applied intervention and might expect their children to have a reduced asthma-like morbidity, whereas in the control group no such "placebo" effect is to be expected. GPs in the intervention group were also not blinded for the intervention, and this could have influenced their interpretation of the observed symptoms and their diagnostic labelling. However, it was found that both the parents and GPs allocated to the intervention group reported and classified asthma-like symptoms less frequently in the female children than in the male children, and it is unlikely that a reporting bias is influenced by sex.

Several randomised intervention studies have reported results on various clinical symptoms at age $1[17,20,34], 2[18,35], 3$ [36], 4 [37] and 8 yrs [19]. When the results of intervention studies are compared, it has to be kept in mind that comparison is hampered, as the studies differ in defining high-risk cases, the applied intervention(s) and the definition of outcomes. In the Manchester Allergy and Asthma Study ( ${ }^{\text {nac }}$ MAAS) study $[36,38]$, stringent anti-mite measures were provided in the homes of expecting atopic parents, where the mothers had to be at least sensitised for mite, cat or dog allergens, as shown by skin testing, but who had no cats or dogs. A significant reduction of (reported) severe wheeze with breathlessness and with exertion at age 1 yr was found [38], as well as a better specific airway resistance in the intervention group at 3 yrs [36]. The Prevention and Incidence of Asthma and Mite Allergy (PIAMA study) [18] recruited pregnant females at high risk on the basis of a reported personal history of asthma, hay fever or reported allergy for house dust, mite or pet allergens. Anti-mite covers for crib and parental mattresses and pillows were provided. At 2 yrs, only a slight but significant reduction in reported night-time cough without a cold was reported, whereas the other (ISAAC) outcomes were not significantly different. The small improvement in the PIAMA study was attributed by the authors to pre-existent low mite levels. However, in the PREVASC study, low mite levels at baseline were also found. In contrast to the PIAMA study, the data presented here show a more pronounced effect of the

\begin{tabular}{|c|c|c|c|c|c|c|}
\hline & \multicolumn{2}{|c|}{ Total } & \multicolumn{2}{|c|}{ Males } & \multicolumn{2}{|c|}{ Females } \\
\hline & Intervention & Control & Intervention & Control & Intervention & Control \\
\hline Total IgE IU $\cdot \mathrm{mL}^{-1}$ & $2.6 \pm 1.4$ & $2.6 \pm 1.4$ & $2.8 \pm 1.4$ & $2.8 \pm 1.4$ & $2.5 \pm 1.3$ & $2.5 \pm 1.4$ \\
\hline \multicolumn{7}{|c|}{ Presence of specific ${ }^{\#}$ IgE against } \\
\hline Cat & $6.9(7 / 192)$ & $5.7(12 / 209)$ & $6.7(7 / 105)$ & $7.8(8 / 103)$ & $0.0(0 / 87)$ & $3.8(4 / 106)$ \\
\hline Dog & $4.9(9 / 185)$ & $4.8(10 / 208)$ & 6.9 (7/102) & $5.86 / 103$ & $2.4(2 / 83)$ & $3.8(4 / 105)$ \\
\hline
\end{tabular}

Data are presented as $\%(\mathrm{n} / \mathrm{N})$ or geometric mean $\pm \mathrm{SD}$. ${ }^{\#}$ : positive RAST $\geqslant 0.35 \mathrm{IU} \cdot \mathrm{mL}^{-1}$. No significant differences were found between the intervention and control groups for total IgE (t-test) or for specific IgE (Chi-squared test). 


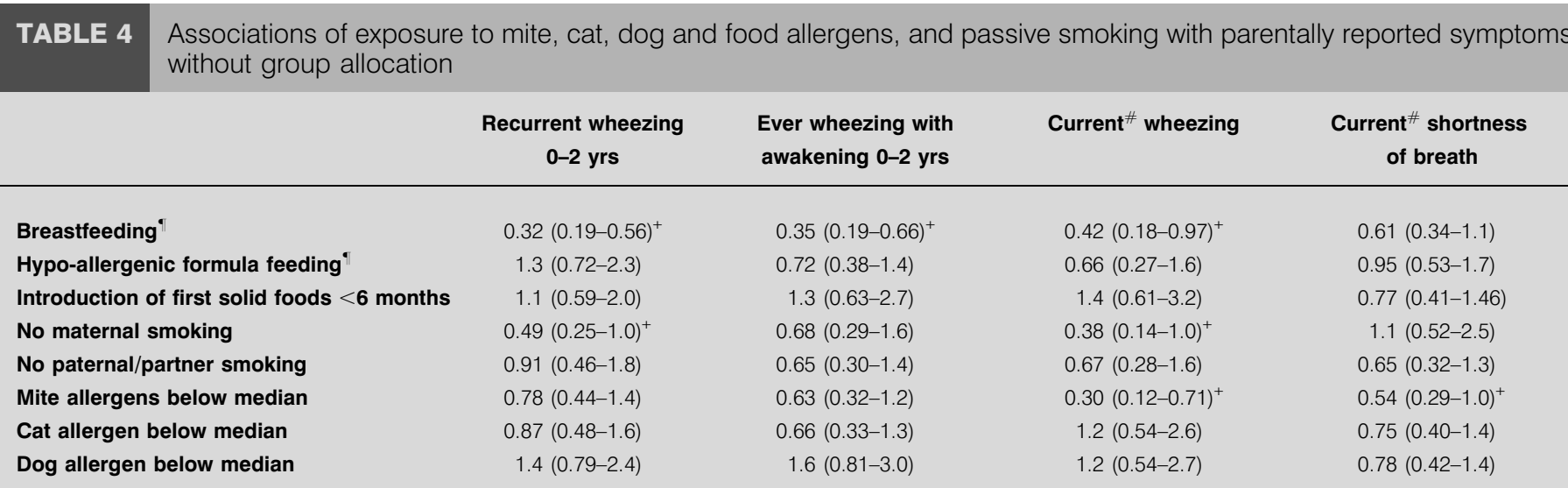

Data are the results of the multiple logistic regression analysis and are presented as odds ratio (OR) (95\% confidence interval). ORs are adjusted for the other listed exposures. ${ }^{*}$ : at least one episode in the 4 weeks before the 2 nd birthday; ${ }^{\circ}$ : ever breastfed or hypo-allergenic bottle fed; ${ }^{+}$: significant effect.

intervention at 2 yrs, not only on night-time cough but also on other asthma-like symptoms, which might be explained by the multifaceted approach used in the PREVASC study. The Isle of Wight study [19] defined high-risk cases when allergy in at least two first-degree relatives or in one first-degree relative with an elevated cord blood $\operatorname{IgE}$ was present. A dual preventive approach was used, i.e. encasement of the crib mattress (not the parental mattress) and maternal avoidance of food allergens during lactation. At age $8 \mathrm{yrs}$, the intervention group was found to be at a significantly reduced risk for wheeze in the past year, nocturnal cough and mite sensitisation; however, the numbers were small because of the relatively high drop-out rate [19]. A Canadian intervention study $[39,40]$ had a university hospital-based setting, used comparable inclusion criteria and also carried out a multifaceted intervention like the PREVASC study. In their study, the clinical outcome (probable or possible asthma diagnosed by paediatric allergists) at age 2 yrs was significantly (significance one-sided tested) less present in the intervention group (16\%) than in the control group (23\%) [40]. A comparable difference was found in GP-diagnosed asthma in the PREVASC study, although this difference, tested twosided, did not reach statistical significance.

The Childhood Asthma Prevention (CAPS) study [41] focused on mite allergen avoidance and/or supplementation with omega- 3 fatty acids. The mite intervention was associated with lower use of oral steroids but not with wheeze, serum $\operatorname{IgE}$, atopy or doctor-diagnosed asthma. However, the diet intervention resulted in a lower parentally reported prevalence of wheeze during the first 18 months.

In this study, no significant effect of the intervention was found on the incidence of specific IgE against mite, cat and dog allergen at age 2 yrs. In addition, the Canadian study [40], the PIAMA [18], the CAPS study [41] and the Study of Prevention of Allergy in Children in Europe (SPACE) [35] all found no effect of the intervention on mite sensitisation at age $2 \mathrm{yrs}$, while the nac MAAS study reported that the stringent mite avoidance regime was associated with an increased risk [36]. One explanation for this might be that the intervention was started too late, as sensitisation might already have occurred in utero $[42,43]$.

In the present study, it was shown that it is possible to reduce exposure to mite, pet and food allergens, but not to passive smoking. The main reduction in mite levels was attained in mattress dust by the use of anti-mite encasings. In general, low pre-intervention levels of mite and pet allergens were found at baseline, probably as a result of (already) successful efforts of asthmatic families to achieve a low-allergen environment, as reported previously [44]. In spite of the pre-existent low mite level, infants with mite allergen levels below the median had a reduced risk of current asthma-like symptoms when compared to infants exposed to levels above the median.

Multiple logistic regression analyses of the relationship between exposure and asthma-like (wheezing) symptoms revealed that exposure to mite and food allergens, and passive smoking contributed, independently of each other, to asthmalike symptoms, confirming that asthma is a multifactorial disease. A reduction of a single exposure seems to be less effective, as is supported by recent reports. A large observational birth cohort study [45] in Sweden analysed the effect of living in agreement with three prevailing preventive measures: avoidance of maternal smoking, breastfeeding the infant and reduction of home dampness. Children of families who had applied all three measures had less wheeze and asthma than children of families who executed only two measures. The studies might explain why avoidance of a single exposure has only marginal or no effects when other exposures are still existing, as might have been the case in other prevention studies [18, 35]. In tertiary prevention of asthma intervention studies [46], focusing on a reduction of multiple environmental exposures has shown promising results, whereas the results of clinical trials targeting only one allergen were disappointing $[47,48]$. These studies and the current findings are a plea in favour of pursuing a multifaceted approach with respect to the prevention of asthma.

In contrast to most other intervention studies, the PREVASC study was designed to work in primary care, by approximating 
regular primary care circumstances as well as possible. This is important if and when the intervention, once proven to be effective to prevent asthma, becomes part of regular primary care. As has been shown in the PREVASC study, GPs and midwives were able to identify high-risk cases during routine consultation in early pregnancy. The intervention can be initiated in primary care, as was done in the research setting and executed with the help of practice nurses and/or wellbaby clinics.

In a post hoc analysis, it was observed that the clinical effect of the intervention was mainly confined to females in the intervention group. To the current authors' knowledge, this is the first intervention study reporting that sex might modify the effect of reduction of environmental exposure on symptoms. The difference between the male and female groups was striking, and very consistent for almost all outcomes derived from three sources, which makes chance as an explanation less likely. For specific IgE, a nonsignificant trend for a sex-specific intervention effect was also observed. However, post hoc analyses do not allow conclusions to be drawn, but only present the possibility of the modification by sex as a suggestive hypothesis. So far, the results permit a speculative explanation of a possible effect modification by sex, although there is support in the literature for this interesting observation. Airway physiology and pathology during the whole life span, starting in the intrauterine period, is subjected to the influence of sex and might be under hormonal control, as reviewed by BECKLAKE and KAUFFMANN [21]. Airways of male infants are smaller than those of female infants, resulting in a lower lung function of young males [49]. Studies report that symptoms induced by environmental exposure are influenced by sex. When exposed to passive tobacco smoking in utero, lung function of young males with asthma is lower than of young females with asthma [50]. Pet-owning females are more susceptible to asthma when they also smoke [22]. Lung function in females, if sensitised by cat and pollen allergens, is more affected than in males [51]. The production of IgE is also influenced by sex, as the concentration of total serum $\operatorname{IgE}$ was higher in the males than the females. On the basis of these observations, one might hypothesise that, given the different reactions of the male and female immune systems to environmental exposure, males and females might also react differently to a reduction in relevant exposures. Sex-specific effects of the intervention should be evaluated in further (prospective) research, and it would be interesting if all ongoing cohort studies included information specifying whether a sex difference can be detected.

In conclusion, no effect of a multifaceted intervention programme was found on asthma-like symptoms in high-risk children during their first 2 yrs of life and atopic sensitisation at age 2 yrs. However, a small effect was observed on the symptoms at the end of their 2nd yr of life. Further follow-up is necessary to determine whether the intervention measures can actually prevent the development of asthma.

\section{ACKNOWLEDGEMENTS}

The PREVASC study is a joint project of the Depts of General Practice of the University of Maastricht and the Radboud University of Nijmegen. The authors would like to thank the GPs allied to these departments and the participating midwives for recruiting eligible families. The authors are grateful to all families who readily participated in the project. The authors would also like to thank: the research assistants, I. van Beerendonck and K. Manders; the data managers, J. Pisters and K. Coolen; the statistical adviser, J. Sijbrandij; the nurses, who visited and instructed the participating families, C. Brink, K. van der Meer, M. Rovers, T. Jeijsman, I. Schaap, M. Terhaar and E. de Vree; and the PREVASC secretary, A. Spaninks. The authors thank Numico NV (Zoetermeer, The Netherlands) for the supply of Nutrilon pepti® and Sanalife (Lelystad, The Netherlands) for the supply of the house dust mite impermeable covers (Mitecare ${ }^{\circledR}$ ) and bedding. They would also like to thank N. van der Maas of Skiltec B.V., Beek, The Netherlands, for his linguistic comments and suggestions.

\section{REFERENCES}

1 Lenney W. The burden of pediatric asthma. Pediatr Pulmonol Suppl 1997; 15: 13-16.

2 Wever-Hess J, Wever AM, Yntema JL. Mortality and morbidity from respiratory diseases in childhood in The Netherlands, 1980-1987. Eur Respir J 1991; 4: 429-433.

3 Gustafsson PA. Family dysfunction in asthma: results from a prospective study of the development of childhood atopic illness. Pediatr Pulmonol Suppl 1997; 16: 262-264.

4 Burney PG, Chinn S, Rona RJ. Has the prevalence of asthma increased in children? Evidence from the national study of health and growth 1973-86. BMJ 1990; 300: 1306-1310.

5 Lewis S, Butland B, Strachan D, et al. Study of the aetiology of wheezing illness at age 16 in two national British birth cohorts. Thorax 1996; 51: 670-676.

6 Downs SH, Marks GB, Sporik R, Belosouva EG, Car NG, Peat JK. Continued increase in the prevalence of asthma and atopy. Arch Dis Child 2001; 84: 20-23.

7 Upton MN, McConnachie A, McSharry C, et al. Intergenerational 20 year trends in the prevalence of asthma and hay fever in adults: the Midspan family study surveys of parents and offspring. BMJ 2000; 321: 88-92.

8 Tirimanna PR, van Schayck CP, den Otter JJ, et al. Prevalence of asthma and COPD in general practice in 1992: has it changed since 1977? Br J Gen Pract 1996; 46: 277-281.

9 Warner JA, Jones AC, Miles EA, Colwell BM, Warner JO. Prenatal origins of asthma and allergy. Ciba Found Symp 1997; 206: 220-228.

10 Holloway JA, Warner JO, Vance GH, Diaper ND, Warner JA, Jones CA. Detection of house-dust-mite allergen in amniotic fluid and umbilical-cord blood. Lancet 2000; 356: 1900-1902.

11 Holt PG, Macaubas C, Sly PD. Strategic targets for primary prevention of allergic disease in childhood. Allergy 1998; 53: 72-76.

12 Tariq SM. Allergen avoidance in the primary prevention of atopy. Br J Clin Pract 1996; 50: 99-102.

13 Dold S, Wjst M, von Mutius E, Reitmeir P, Stiepel E. Genetic risk for asthma, allergic rhinitis, and atopic dermatitis. Arch Dis Child 1992; 67: 1018-1022.

14 Schonberger HJ, Van Schayck CP. Prevention of asthma in genetically predisposed children in primary care-from clinical efficacy to a feasible intervention programme. Clin Exp Allergy 1998; 28: 1325-1331. 
15 Gore C, Custovic A. Preventive measures and their effects. Results from cohort studies. Paediatr Respir Rev 2002; 3: 205-218.

16 Exl BM, Deland U, Secretin MC, Preysch U, Wall M, Shmerling $\mathrm{DH}$. Improved general health status in an unselected infant population following an allergen reduced dietary intervention programme. The ZUFFstudy-programme. Part I: Study design and 6-month nutritional behaviour. Eur J Nutr 2000; 39: 89-102.

17 Custovic A, Simpson BM, Simpson A, Kissen P, Woodcock A. Effect of environmental manipulation in pregnancy and early life on respiratory symptoms and atopy during first year of life: a randomised trial. Lancet 2001; 358: 188-193.

18 Koopman LP, van Strien RT, Kerkhof M, et al. Placebocontrolled trial of house dust mite-impermeable mattress covers: effect on symptoms in early childhood. Am J Respir Crit Care Med 2002; 166: 307-313.

19 Arshad SH, Bateman B, Matthews SM. Primary prevention of asthma and atopy during childhood by allergen avoidance in infancy: a randomised controlled study. Thorax 2003; 58: 489-493.

20 Chan-Yeung M, Manfreda J, Dimich-Ward H, Ferguson A, Watson W, Becker A. A randomized controlled study on the effectiveness of a multifaceted intervention program in the primary prevention of asthma in high-risk infants. Arch Pediatr Adolesc Med 2000; 154: 657-663.

21 Becklake MR, Kauffmann F. Gender differences in airway behaviour over the human life span. Thorax 1999; 54: 1119-1138.

22 Chen Y, Dales R, Tang M, Krewski D. Sex-related interactive effect of smoking and household pets on asthma incidence. Eur Respir J 2002; 20: 1162-1166.

23 Schonberger HJAM, Maas T, Dompeling E, Knottnerus JA, van Weel C, van Schayck CP. Compliance of asthmatic families with a primary prevention programme of asthma and effectiveness of measures to reduce inhalant allergens - a randomized trial. Clin Exp Allergy 2004; 34: 1024-1031.

24 van Weel C. International research and the discipline of family medicine. Eur J Gen Pract 1999; 5: 110-114.

25 Dirksen WJ, Geijer RMM, de Haan M, de Koning G, Flikweert S, Kolnaar BGM. NHG-Standaard Astma bij Kinderen (eerste herziening) [Guideliness of asthma in childhood (first revision)]. Huisarts Wet 1998; 41: 130-143.

26 Asher MI, Keil U, Anderson HR, et al. International Study of Asthma and Allergies in Childhood (ISAAC): rationale and methods. Eur Respir J 1995; 8: 483-491.

27 WONCA CCo. An international glossary for primary care. In: Classification Committee of WONCA in collaboration with the WHO. ICHPCC-2-defined. 3rd Edn. London, Oxford University Press, 1983.

28 Aalberse RC, Koshte V, Clemens JG. Immunoglobulin E antibodies that crossreact with vegetable foods, pollen, and Hymenoptera venom. J Allergy Clin Immunol 1981; 68: 356-364.

29 Meijer GG, Postma DS, van der Heide S, et al. Seasonal variations in house dust mite influence the circadian peak expiratory flow amplitude. Am J Respir Crit Care Med 1996; 154: 881-884.

30 van der Heide S, van Aalderen WM, Kauffman HF, Dubois AE, de Monchy JG. Clinical effects of air cleaners in homes of asthmatic children sensitized to pet allergens J Allergy Clin Immunol 1999; 104: 447-451.

31 Luczynska CM. Identification and quantification of mite allergens. Allergy 1998; 53: Suppl. 48, 54-57.

32 Zelen M. A new design for randomized clinical trials. N Engl J Med 1979; 300: 1242-1245.

33 Nelson EA, Taylor BJ, Jenik A, et al. International Child Care Practices Study: infant sleeping environment. Early Hum Dev 2001; 62: 43-55.

34 Tsitoura S, Nestoridou K, Botis $\mathrm{P}$, et al. Randomized trial to prevent sensitization to mite allergens in toddlers and preschoolers by allergen reduction and education: oneyear results. Arch Pediatr Adolesc Med 2002; 156: 1021-1027.

35 Horak F, Matthews S, Ihorst G, et al. Effect of miteimpermeable mattress encasings and an educational package on the development of allergies in a multinational randomized, controlled birth-cohort study - 24 months results of the Study of Prevention of Allergy in Children in Europe. Clin Exp Allergy 2004; 34: 1220-1225.

36 Woodcock A, Lowe LA, Murray CS, et al. Early life environmental control: effect on symptoms, sensitization, and lung function at age 3 years. Am J Respir Crit Care Med 2004; 170: 433-439.

37 Hide DW, Matthews S, Tariq S, Arshad SH. Allergen avoidance in infancy and allergy at 4 years of age. Allergy 1996; 51: 89-93.

38 Custovic A, Simpson BM, Simpson A, et al. Manchester Asthma and Allergy Study: low-allergen environment can be achieved and maintained during pregnancy and in early life. J Allergy Clin Immunol 2000; 105: 252-258.

39 Chan-Yeung M, Ferguson A, Dimich-Ward H, Watson W, Manfreda J, Becker A. Effectiveness of and compliance to intervention measures in reducing house dust and cat allergens levels. Ann Allergy Asthma Immunol 2002; 88: 52-58.

40 Becker A, Watson W, Ferguson A, Dimich-Ward H, ChanYeung $\mathrm{M}$. The Canadian asthma primary prevention study: outcomes at 2 years of age. J Allergy Clin Immunol 2004; 113: 650-656.

41 Mihrshahi S, Peat J, Marks G, et al. Eighteen-month outcomes of house dust mite avoidance and dietary fatty acid modification in the childhood asthma prevention study (CAPS). J Allergy Clin Immunol 2003; 111: 162-168.

42 Miller RL, Chew GL, Bell CA, et al. Prenatal exposure, maternal sensitization, and sensitization in utero to indoor allergens in an inner-city cohort. Am J Respir Crit Care Med 2001; 164: 995-1001.

43 Warner JA, Jones CA, Jones AC, Miles EA, Francis T, Warner JO. Immune responses during pregnancy and the development of allergic disease. Pediatr Allergy Immunol 1997; 8: Suppl. 10, 5-10.

44 Wijga A, Smit HA, Brunekreef B, et al. Are children at high familial risk of developing allergy born into a low risk environment? The PIAMA Birth Cohort Study. Prevention and Incidence of Asthma and Mite Allergy. Clin Exp Allergy 2001; 31: 576-581.

45 Wickman M, Melen E, Berglind N, et al. Strategies for preventing wheezing and asthma in small children. Allergy 2003; 58: 742-747.

46 Rijssenbeek-Nouwens LHM, Oosting AJ, de BruinWeller MS, Bregman I, de Monchy JGR, Postma DS. 
Clinical evaluation of the effect of anti-allergic mattress covers in patients with moderate to severe asthma and house dust mite allergy: a randomised double blind placebo controlled study. Thorax 2002; 57: 784-790.

47 Morgan WJ, Crain EF, Gruchalla RS, et al. Results of a home-based environmental intervention among urban children with asthma. N Engl J Med 2004; 351: 10681080.

48 Woodcock A, Forster L, Matthews E, et al. Control of exposure to mite allergen and allergen-impermeable bed covers for adults with asthma. N Engl J Med 2003; 349: 225-236.
49 Young S, Arnott J, O'Keeffe PT, Le Souef PN, Landau LI. The association between early life lung function and wheezing during the first 2 yrs of life. Eur Respir J 2000; 15: 151-157.

50 Li YF, Gilliland FD, Berhane K, et al. Effects of in utero and environmental tobacco smoke exposure on lung function in boys and girls with and without asthma. Am J Respir Crit Care Med 2000; 162: 2097-2104.

51 Sunyer J, Soriano J, Anto JM, et al. Sensitization to individual allergens as risk factors for lower FEV1 in young adults. European Community Respiratory Health Survey. Int J Epidemiol 2000; 29: 125-130. 